Afr. J. Trad. CAM (2004) 1: 1- 3

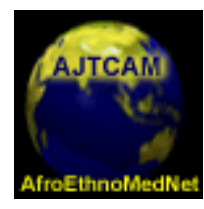

Editorial

Afr. J. Traditional, Complementary and

Alternative Medicines

www.africanethnomedicines.net

\title{
SAFETY OF TRADITIONAL MEDICINES, COMPLEMENTARY AND ALTERNATIVE MEDICINES IN AFRICA
}

\author{
C. O. Adewunmi and J. A. O. Ojewole \\ Drug Research and Production Unit, Faculty of Pharmacy, \\ Obafemi Awolowo University, Ile-Ife, Nigeria and Department of Pharmacology, \\ Faculty of Health Sciences, University of Kwazulu Natal, Durban, South Africa \\ E-mail:editor@africanethnomedicines.net
}

Plants have been used for medicinal purposes in Africa for many centuries. Today, herbal products are being used worldwide in a variety of healthcare settings, and as a home remedies. Herbal products are often promoted to the public as being "natural" and completely "safe" alternatives to conventional medicines. African plants used medicinally are widely assumed to be safe, but many are potentially toxic (Fennell et al., 2004). The efficacy, safety and quality of raw medicinal plant materials and plant products depend on intrinsic or external factors. Inadvertent contamination by microbial or chemical agents during any of the production stages can also affect the quality, safety and efficacy. Medicinal plants collected in the wild may be contaminated by other species or plant parts through misidentification, accidental contamination or intentional adulteration, all of which may have unsafe consequences.

Herbal medicines (sometimes referred to as 'phytomedicines') exhibit some peculiar characteristics, namely: the active principles are frequently unknown; standardization, stability and quality control are feasible but not easy; the availability and quality of raw materials are frequently problematic; well-controlled, double-blind clinical and toxicological studies to prove their efficacy and safety are rare; empirical use in folk medicine is a very important characteristic; they have a wide range of therapeutic uses and are suitable for chronic treatments; the occurrence of undesirable side effects seems to be less frequent with herbal medicines, but well-controlled, randomized clinical trials have revealed that they also exist; they are usually affordable and cost less than synthetic drugs (Calixto, 2000).

It is probable that adverse reactions to herbal products are under-reported because it is well known that patients are reluctant to inform their doctors that they are taking herbal products (Barnes et. al., 1998). Furthermore, majority of these products are self-prescribed and are used to treat, manage or control both minor and chronic ailments. Some 'traditional, complementary and alternative medicines' (TCAM) contain toxic and potentially lethal constituents. These constituents include aristolochic acids, pyrrolizidine alkaloids, benzophenanthrine alkaloids, lectins, viscotoxins, 


\section{Afr. J. Trad. CAM (2004) 1: 1- 3}

saponins, diterpenes, cyanogenetic glycosides and furanocoumarins. The quality of the product/s is an important factor because it can affect the efficacy and/or safety of the herbal products being used (Fong, 2002). Concerns over unregulated herbal products are further compounded by demand outstripping supply of good quality ingredients, confusing nomenclature over plant species, cultural differences and traditional practices. Cases of nephropathy involving substitution of Aristolochia fangchi and Stephania tetrandra, and substitution of Aristolochia manshuriensis stem for the stem of Clematis and Akebia species (EMEA, 2001) have been reported. Recent report of the detectable amounts of aristolochic acid I and II in $24.0 \%$ of the Traditional Chinese Medicines containing either Aristolochia or Asarum as an ingredient despite the fact that FDA has advised industry to remove products on the market thought to contain aristolochic acid since 2001, products are still present on the market for consumption (Schaneberg and Khan, 2004). There is evidence that "where poisoning from traditional medicines has been reported, it is usually because the plants used have been misidentified in the form in which they are sold, or incorrectly prepared and administered by inadequately trained personnel” (Fennell et al., 2004).

Herbal ingredients must be accurately identified by macroscopical and microscopical comparison with authentic material, or accurate descriptions of authentic herbs (Houghton, 1998). It is essential that herbal ingredients are referred to by their binomial Latin names of genus and species; only permitted synonyms should be used. Over-the-counter (OTC) health foods, nutraceuticals, and medicinal products from plants may be contaminated with excessive or banned pesticides, microbial contaminants, heavy metals, chemical toxins; and adulterated with orthodox drugs (Chan, 2003). There are concerns, however, that products imported from outside the European community (EU) may have been treated with a fumigant (Baldwin et al., 1986; MCA, 2002).

Herb-food and herb-drug interactions may be pharmacodynamic or pharmacokinetic (MCA, 2002). Case reports of potentially hazardous interactions due to drug combinations with St. John's wort have been published. Furthermore, herbs containing substantial levels of coumarins may potentially increase blood coagulation time if taken in large doses. Of special concern is the ability of herbal remedies to potentiate effects of prescription drugs with narrow safety margins or therapeutic windows (Aggarwal and Ades, 2001).

Few conventional medicines have been established as 'safe' to take during pregnancy, and it is generally recognised that no medicine should be taken unless the benefit to the mother outweighs any possible risk to the foetus. This rule should also be applied to herbal products. Some herbal teas also contain laxative herbal ingredients such as senna, frangula, and cascara. In general, stimulant laxative preparations are not recommended during pregnancy, and the use of unstandardised herbal laxative preparations should be avoided in pregnancy. The use of unstandardised herbal remedies should also be avoided during lactation because some of the herbal products may contain harmful constituents excreted in breast milk. 
Afr. J. Trad. CAM (2004) 1: 1- 3

It is crucially important that regulatory studies are conducted prior to exposure of human beings to herbal products. Until when toxicological, pharmacodynamic and pharmacokinetic data are available, traditional health practitioners and clinicians must exercise caution in prescribing concurrently to their patients. The potential for drug-herbal interactions should always be borne in mind by the therapists. Conventional therapies should focus on treatment with proven, evidence-based strategies (Miller et al., 2004).

It is essential that information on the risks associated with the use of herbal products is systematically collected and analysed in order to protect patients and the public at large.

\section{References}

1) Aggarwal, A. and Ades, A. (2001). Interactions of herbal remedies with prescription cardiovascular medications. Coron Artery Dis. 12:581-584.

2) Baldwin C. A. Anderson, L. A. and Phillipson, J. D. (1986). What pharmacists should know about ginseng? Pharm $J$ 237: 583-586.

3) Barnes J., Mills, S. Y., Abbot, N. C., Willoughby, M. and Ernst, E. (1988). Different standards for reporting ADRs to herbal remedies and conventional OTC medicines: face-toface interviews with 515 users of herbal remedies. Br J Clin Pharmacol. 45: 496-500.

4) Calixto, J. B. (2000). Efficacy, safety, quality control, marketing and regulatory guidelines for herbal medicines (phytotherapeutic agents). Braz. J. Med. Biol. Res. 33: 179-189.

5) Chan, K. (2003). Some aspects of toxic contaminants in herbal medicines. Chemosphere 52:1361-71

6) EMEA (2001). Herbal Medicinal Products Working Party. Position paper on the risks associated with the use of herbal products containing Aristolochia species. EMEA website:www.eudra.org/emea.html. October 2001.

7) Fennell, C.W., Lindsey, K. L., McGaw, L. J., Sparg, L. G., Stafford, G. I. Elgorashi, E. E., Grace, O. M. and van Staden, J (2004). Assessing African medicinal plants for efficacy and safety: pharmacological screening and toxicology. J. Ethnopharmacol. 94: 205-217.

8) Fong, H. H. (2002). Integration of herbal medicine into modern medical practices: issues and prospects. Integr Cancer Ther 1:287-293.

9) Houghton, P. (1998). Establishing Identification Criteria for Botanicals. Drug Information Journal.32:461-469.

10) MCA (2002). Safety of herbal medicinal products. A Report. MCA, UK.

11) Miller, K. L., Liebowitz, R. S. and Newby, L. K. (2004). Complementary and alternative medicine in cardiovascular disease: a review of biologically based approaches. Am Heart J 147:401-11

12) Schaneberg, B.T., Khan, I. A. (2004). Analysis of products suspected of containing Aristolochia or Asarum species. J. Ethnopharmacol.

94: 245-249. 